\title{
Low-pressure endoscopy using the gel immersion method facilitates endoscopic variceal ligation of ruptured esophageal varices
}

Although endoscopic variceal ligation $(E V L)$ is a standard procedure in the management of acute variceal bleeding [1], it is often difficult to secure the visual field because the lumen is filled with fresh blood and the injected water rapidly mixes with blood. For previously treated varices, it may also be difficult to adequately aspirate fibrotic varices into the banding cap.

Gel immersion endoscopy is a new method for securing the visual field using a transparent gel. Because the injected gel does not immediately mix with blood and pushes blood and clots away, the bleeding point can be easily identified within the gel [2]. In addition, the gel immersion method maintains a lower level of intraluminal pressure and wall tension than would be the case with gas insufflation [3], thereby facilitating the aspiration of the varices, even those with fibrosis. However, just before the varices are aspirated, any remaining gel in the accessory channel should be pushed out with air or water, because otherwise it will interfere with the aspiration of the varices.

The patient was a 67-year-old man with ruptured esophageal varices ( $\vee$ Video 1 ). The bleeding point was inadequately identified using gas insufflation ( $>$ Fig. $1 \mathbf{a})$, even after aspirating twice, and the varix could not be drawn into the banding cap owing to high wall tension and the presence of fibrosis from four previous EVL treatments. With the use of the "Viscoclear" gel (Otsuka Pharmaceutical Factory, Tokushima, Japan) [4], the bleeding point was easily identified, while the intraluminal pressure was maintained at a low level ( Fig.1b). Although the varix could not initially be adequately aspirated through the gel-filled channel, after pushing out the remaining gel, the varix was adequately aspirated into the banding cap and successfully banded ( $\triangleright$ Fig. 2 and $>$ Fig. $\mathbf{3}$ ).

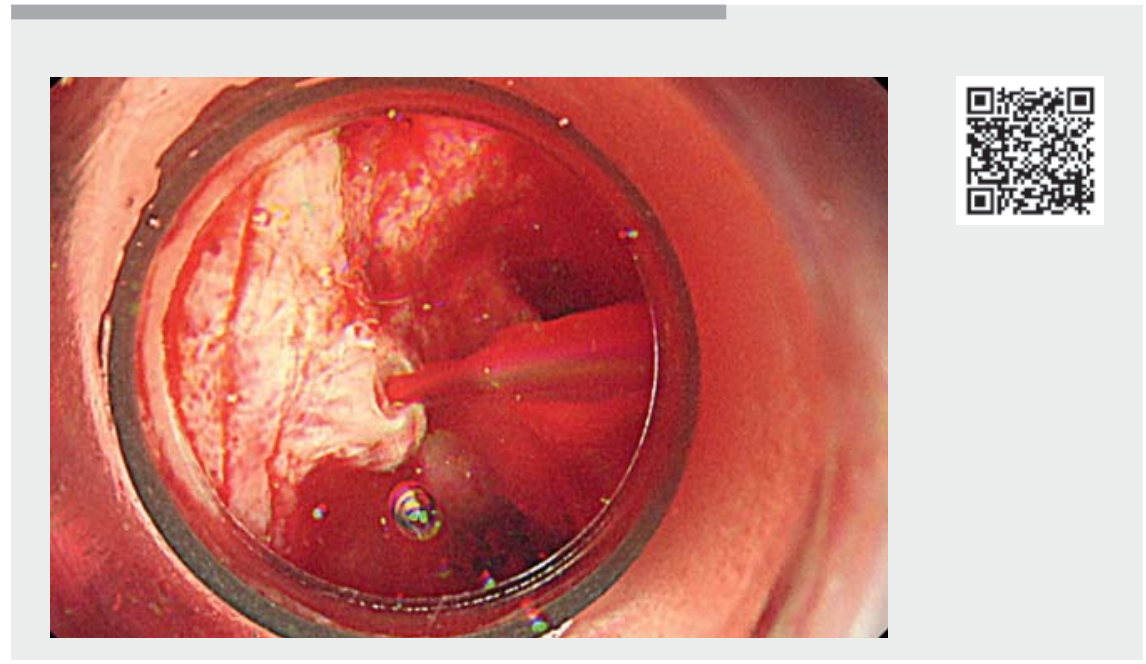

Video 1 The gel immersion method is illustrated and shown being used in a patient with a bleeding esophageal varix, allowing the bleeding point to be easily identified and, after gel remaining in the channel had been pushed out, adequately aspirated and successfully banded.
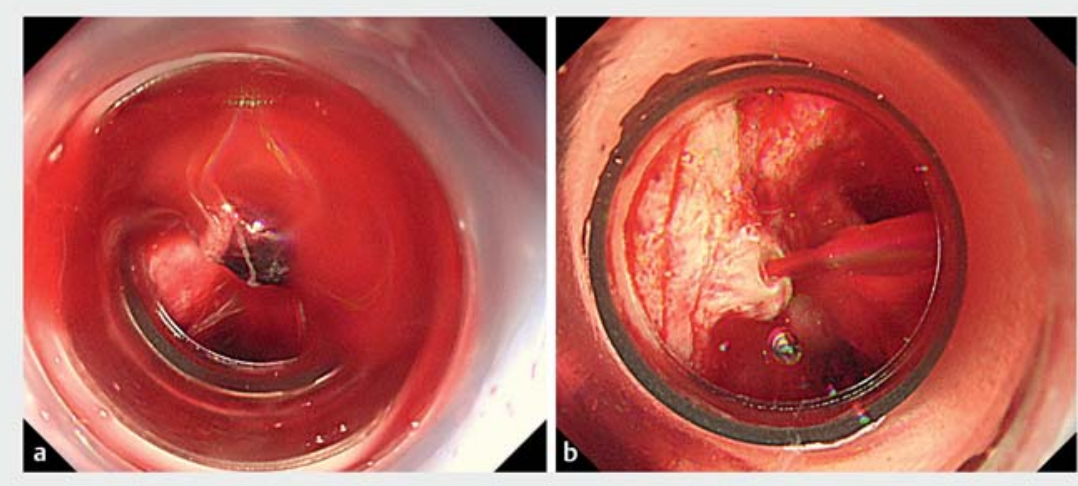

Fig. 1 Endoscopic view showing: a inadequate visualization of the bleeding point when gas insufflation was used; $\mathbf{b}$ the bleeding point, which was easily identified after injection of the gel into the lumen, with the intraluminal pressure also maintained at a low level.

Low-pressure endoscopy using the gel immersion method has the potential to facilitate EVL of ruptured esophageal varices with fibrosis.

Endoscopy_UCTN_Code_TTT_1AO_2AD

\section{Competing interests}

Tomonori Yano has patents for the dedicated electrolyte-free gel. The remaining authors declare that they have no conflict of interest. 


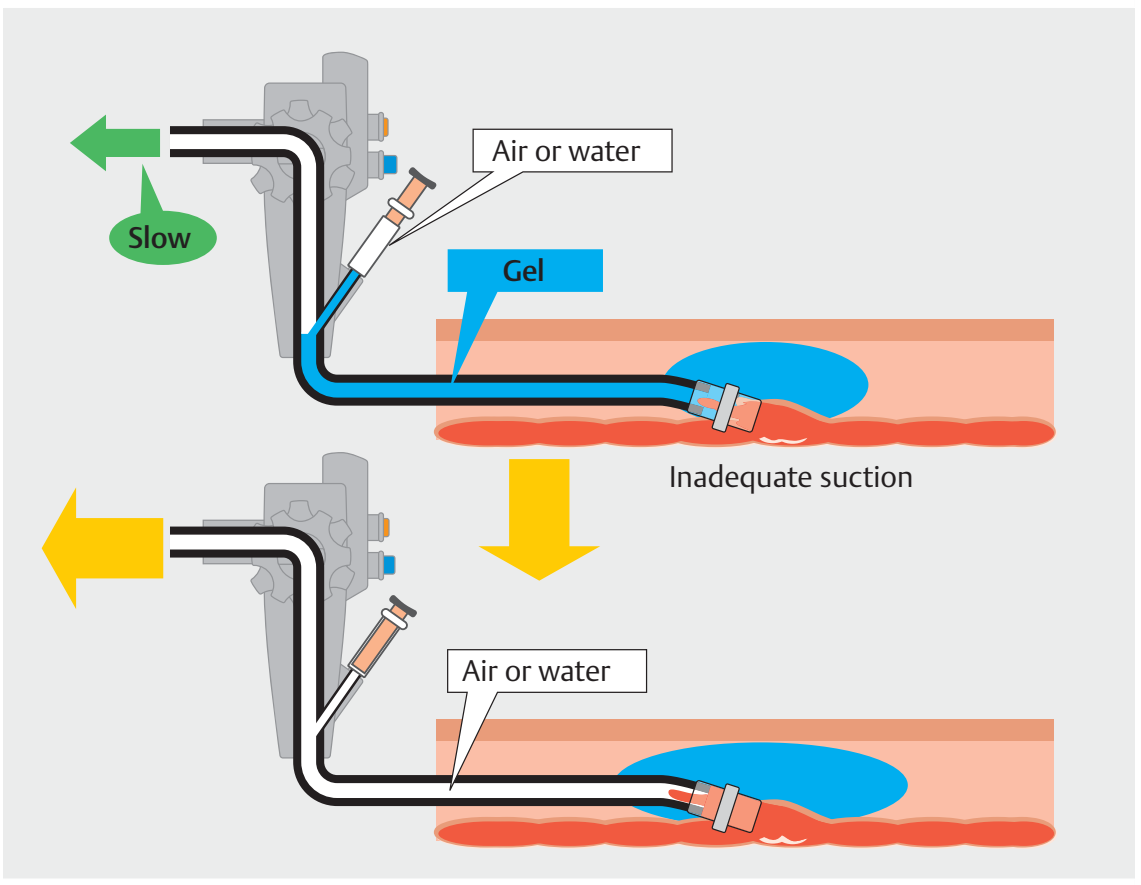

- Fig.2 Diagram illustrating how the viscosity of the gel remaining in the channel made aspiration of the varices slow and difficult, with the procedure requiring any remaining gel to be pushed out with air or water.

The authors

Hiromi Sekiguchi $^{1,2}$, Tomonori Yano ${ }^{1}$, Shinnosuke Tokoro ${ }^{1,2}$, Mizuho lida $^{1,2}$, Shigeo Tano $^{2}$, Alan Kawarai Lefor ${ }^{3}$, Hironori Yamamoto ${ }^{1 \odot}$

1 Department of Medicine, Division of Gastroenterology, Jichi Medical University, Tochigi, Japan

2 Department of Gastroenterology, ShinOyama City Hospital, Tochigi, Japan

3 Department of Surgery, Jichi Medical University, Tochigi, Japan

\section{Corresponding author}

\section{Tomonori Yano, MD, PhD}

Department of Medicine, Division of

Gastroenterology, Jichi Medical University, 3311-1 Yakushiji, Shimotsuke,

Tochigi 329-0498, Japan

tomonori@jichi.ac.jp
References

[1] Hwang JH, Shergill AK, Acosta RD et al. The role of endoscopy in the management of variceal hemorrhage. Gastrointest Endosc 2014; 80: 221-227

[2] Yano T, Nemoto D, Ono K et al. Gel immersion endoscopy: a novel method to secure the visual field during endoscopy in bleeding patients (with videos). Gastrointest Endosc 2016; 83: 809-811

[3] Yano K, Yano T, Nagayama M et al. Hemostasis of an actively bleeding lesion at the ileocecal valve by low-pressure endoscopy using the gel immersion technique. VideoGIE 2021; 6: 184-186

[4] Yano T, Ohata A, Hiraki Y et al. Development of a gel dedicated to gel immersion endoscopy. Endosc Int Open 2021; 09: E918-E924

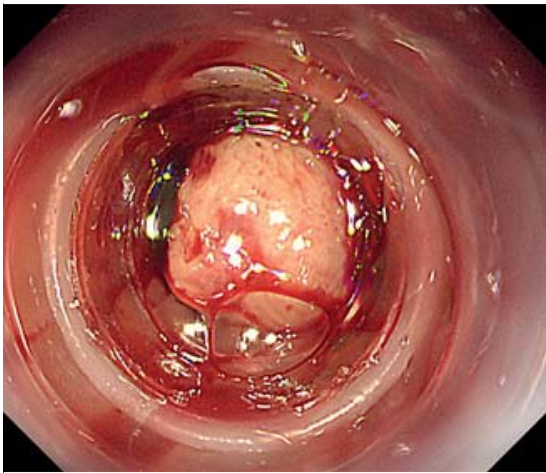

- Fig. 3 Endoscopic view showing the varix adequately aspirated into the banding cap and successfully banded after the gel remaining in the channel had been removed with air.

\section{Bibliography}

Endoscopy 2022; 54: 828-829

DOI 10.1055/a-1559-2120

ISSN 0013-726X

published online 17.9.2021

(C) 2021. Thieme. All rights reserved.

Georg Thieme Verlag KG, Rüdigerstraße 14,

70469 Stuttgart, Germany

\section{ENDOSCOPY E-VIDEOS}

https:|/eref.thieme.de/e-videos

口 Endoscopy E-Videos is a free access online section, reporting 自: on interesting cases and new

techniques in gastroenterological endoscopy. All papers include a high quality video and all contributions are freely accessible online.

This section has its own submission website at https://mc.manuscriptcentral.com/e-videos 